\title{
Cone Features and Parallel Coherencies of F-K Filtered Data-The Processing Significance
}

\author{
Dr. Madu Anthony Joseph Chinenyeze \\ Seismograph Service (Nigeria) Limited SSL, No. 2 Ribadu Rd Race Course Lagos, Nigeria
}

\begin{abstract}
Occurrence of bow-tie or cone-features on $f$-k filtered data and even stack sections were noticed in the course of routine data processing. These features appear to be concordant with trend of seismic signals and can be mistaken for smearing of coherent noise to structural "smiles". These cone features appear to be unique events which emerge after f-k filter application to seismic data, and possess characteristic velocities parallel to those of signal data or primary events. These features can be sufficiently edited or suppressed in post $f-k$ editing, and by appropriate trace scaling or equalization.
\end{abstract}

Keywords: Editing of post-f-k filtered data, Noise attenuation through editing, trace scaling or trace equalization, suppression

\section{Introduction}

There is a significant improvement of quality by applying a selection of frequency dependent editing in cascade of $f$ $\mathrm{k}$ filtered domain. Occurrence of bow-tie or cone-features on $\mathrm{f}-\mathrm{k}$ filtered data and even stack sections were noticed in the course of routine data processing. These features appear to be concordant with trend of seismic signals (figure 1) and can be mistaken for smearing of coherent noise to structural "smiles". These cone features appear to be unique events which emerge after f-k filter application to seismic data, and possess characteristic velocities parallel to those of signal data or primary events.

These features can be sufficiently edited or suppressed in post $\mathrm{f}-\mathrm{k}$ editing. But the result is associated with a slight degradation of the Signal/Noise ratio. The reason is that the cone-features concentrate in patches which may be at early or later time band while the other portions of the affected traces will still retain the normal quality of the data.

These noise features are attenuated by a combination of pre $\mathrm{f}-\mathrm{k}$ editing and post $\mathrm{f}-\mathrm{k}$ editing. This approach results in bi-functional "killing" of as much percentage of signals as the noise component, thus perpetrating the degradation of data. This is due to the overlapping of signal and noise data in the f-k domain.

Analysis of some of these features revealed that they are parallel to signal content, with velocities high enough as those of the data. A modification of the $\mathrm{f}-\mathrm{k}$ filter design can be effected and applied to data, but it does not yield an optimum result. This is because the velocities of some bands of the features are parallel to those of some of the signal (for instance, cone-features velocities ranging from $2000 \mathrm{~m} / \mathrm{s}$ to $2400 \mathrm{~m} / \mathrm{s}$ comparing with the lower velocity band of a full fan accept f-k filter for data in use, -2270 $\mathrm{m} / \mathrm{s}, 2270 \mathrm{~m} / \mathrm{s}, 12 \mathrm{~Hz}, 60 \mathrm{~Hz}$ ).

On the other hand, the range of velocities of these features is rolls (of velocities in the range of $240 \mathrm{~m} / \mathrm{s}$ to $340 \mathrm{~m} / \mathrm{s}$ ). The presence of spikes at some weak traces of delayed first breaks provides further illumination on the search for the source of cone features
Similar features were identified by (Cordell and Henderson 1968, Telford et al 1976) as "artificial events" which can as well result from incorrect migration velocities in any migration algorithm. Hatton et al., 1986 identified these features as artifacts. The latter are caused by problems of trace equalization or Automatic Gain Control (AGC) on $\mathrm{f}-\mathrm{k}$ filtered data. Investigations and experiences show that the appearance of some "processing artifacts" on f-k domain filtering is mostly caused by nonscalar scaling or trace equalization or non-application of Automatic Gain Control (AGC) to appropriate data. The problem is however resolved by suitable application of the mentioned scaling parameters.

\section{Objective}

To find out the cause of cone-features or "processing artifacts" on f-k filtered data.

\section{Methodology}

By use of MicroMAX or ProMAX processing machine, shot records are read into the system in SEG format. The records are edited for the purpose of eliminating the noisy channels. This is synonymous with progressional quality controlling of every signal trace by normal-move-out (NMO) incremental algorithm. The application of F-K filtering across the entire length of record will display a post editing status of noise and bad traces retained in the data. Further editing might degrade the data, but rather attenuated by subsequent $\mathrm{f}-\mathrm{k}$ filtering and stacking.

Figures show both seismic shot record with ox-bow signature and cone-feature noises.

\section{Conclusion}

Appearance of "processing artifacts" on f-k domain filtered data is mostly caused by non-scalar scaling or trace equalization or non-application of Automatic Gain Control (AGC) to appropriate data. The problem is however resolved by suitable application of the trace equalization scaling parameters. 


\section{International Journal of Science and Research (IJSR) \\ ISSN (Online): 2319-7064}

Index Copernicus Value (2013): 6.14 | Impact Factor (2015): 6.391

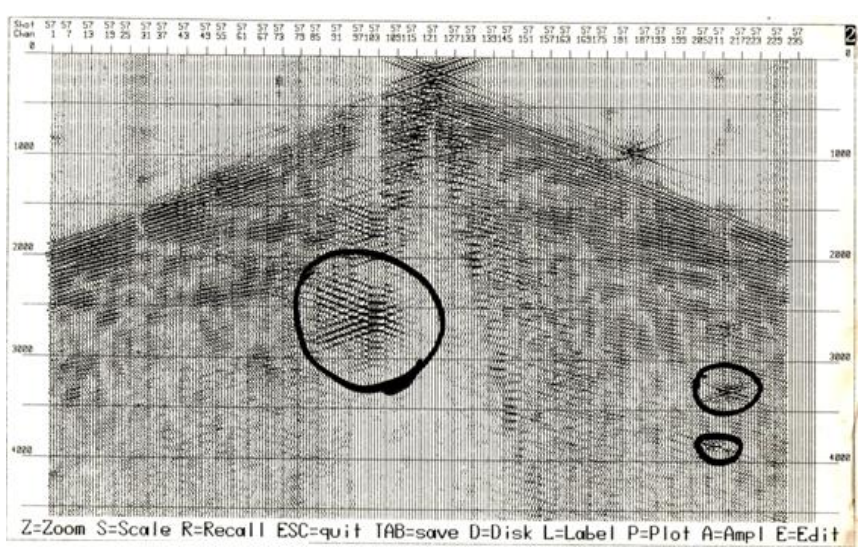

reservoir structure enhancement - Block 10, Yemen, $72^{\text {nd }}$ Ann. Internat. Mtg., Soc. Expl. Geophys., Expanded Abstracts, CHI 3.4.

[5] Nettleton L. L., (1940). Geophysical Prospecting for Oil. McGraw- Hill Book Co. New York. 444p.

[6] Ojo, S. B., and Ajakaiye, D. E., (1976). Preliminary Interpretation of Gravity measurements in the Middle Niger Basin Area, Nigeria. In Geology of Nigeria. (Ed) Kogbe C. A., Elizabethan Publ. Co. Lagos, Pp. $295-307$.

[7] Telford, W. N., Geldert, L. P., Sheriff, R. E., and Keys, D. A., (1976). Applied Geophysics. Oxford Univ. Press New York. 860p

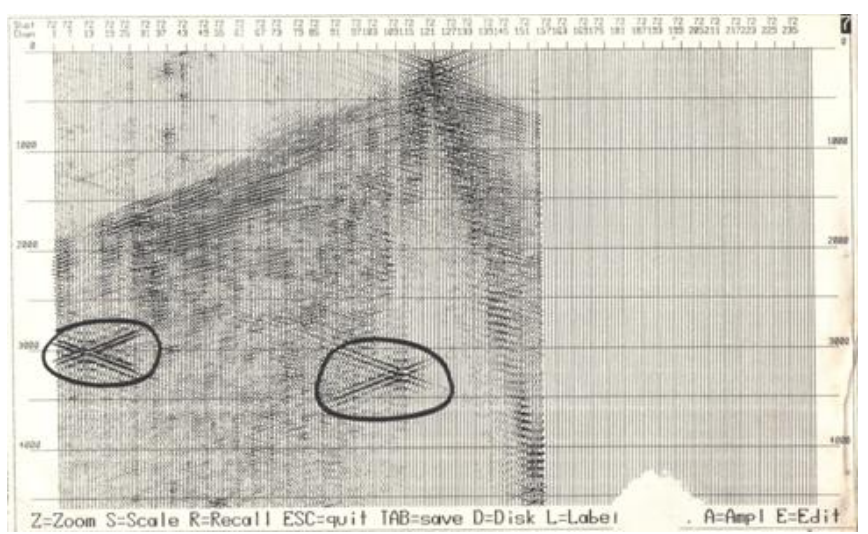

Figure 1a showing shot record with ox-bow signature to cone-feature noises

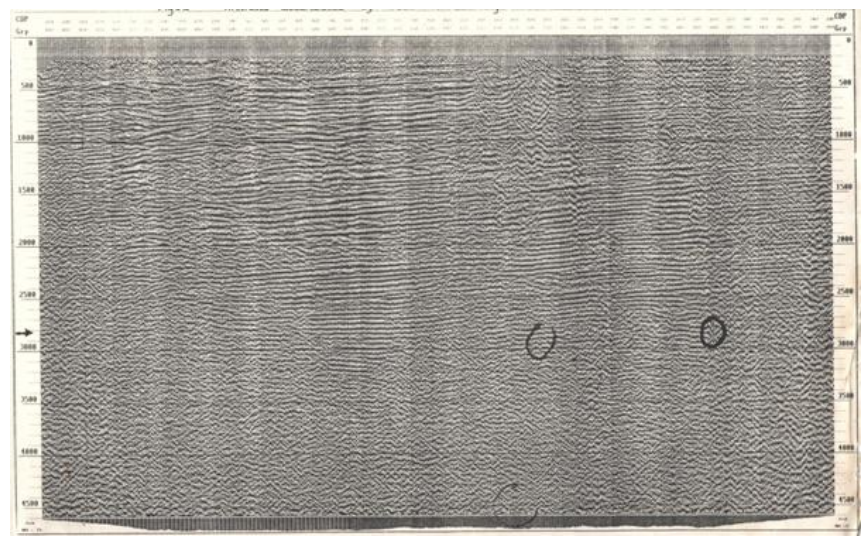

Figure showing Stack after F-K, cone feature attenuated

\section{References}

[1] Cordell, L., and Henderson R. G., (1968). Iterative three-dimensional solution of gravity anomaly data using a digital computer. Geophysics. Vol. 33, Pp. $596-602$.

[2] Dobrin, M. B. (1983). Introduction to Geophysical Prospecting. Mc Graw-Hill Book Co., London. $3^{\text {rd }}$ Ed., $576 \mathrm{p}$.

[3] Eze, C. L., Okwueze, E. E. and Uko, E. D. (2003). The velocity - thickness characteristics of the mangrove swamp low velocity layer (LVL) South central Niger Delta, Nigeria. Global Journal of Pure and Applied Sciences Vol. 9, No. 3, p. 369-374.

[4] Girard, M., Pradalié, F., and Postel, J.J. (2002). Contribution of new technologies and methods for 3D land seismic acquisition and processing applied to 